\title{
PARTIAL PURIFICATION AND SOME BIOCHEMICAL PROPERTIES OF NEONATAL RAT CUTANEOUS GLUTATHIONE S-TRANSFERASES
}

\author{
Arun P. Kulkarni*, John L. Nelson and Louis L. Radulovic \\ Toxicology Program, Department of Environmental and Industrial Health, School of Public Health, The \\ University of Michigan, Ann Arbor, MI 48109-2029, USA
}

(Received 8 September 1986)

\begin{abstract}
Previous studies have demonstrated the presence of glutathione S-transferases in the skin of rodents and humans. This study represents the first attempt to purify cytosolic glutathione S-transferases from skin of 3-day-old rats.

2. A partial purification of the enzyme was achieved by a two-step procedure: affinity chromatography followed by HPLC. Two peaks, one major (P-1) and one minor (P-2), were resolved by HPLC containing about $82 \%$ and $10 \%$ of the recovered activity, respectively.

3. The major form exhibited an overall purification of about 2270 -fold with a specific activity of about $73 \mu \mathrm{moles} / \mathrm{min} / \mathrm{mg}$ protein towards 1-chloro-2,4-dinitrobenzene.

4. The kinetic data for P-1 yielded mean $K_{m}$ values of $2.39 \mathrm{mM}$ for 1-chloro-2,4-dinitrobenzene and $0.72 \mathrm{mM}$ for reduced glutathione, while the respective average $V_{\max }$ values were found to be 212 and $101 \mu \mathrm{moles} / \mathrm{min} / \mathrm{mg}$ protein.

5. Significantly inhibition of enzyme activity was noted in the presence of $0.2 \mathrm{mM} \mathrm{HgCl}_{2}, 0.63 \mu \mathrm{M}$

1.2-naphthoquinone, $1.0 \mu \mathrm{M}$ triphenyltin chloride, and $12.5 \mu \mathrm{M} 17 \beta$-estradiol-3-sulfate.
\end{abstract}

\section{INTRODUCTION}

GSHTr (EC 2.5.1.18) represent a family of highly versatile enzymes which are active in catalyzing the conjugation of GSH with a large number of endogenous and exogenous chemicals bearing an electrophilic center (Chasseaud, 1979; Jakoby and Habig, 1980). GSHTr occur in multiple forms in most tissues and several reports on the purification and characterization of GSHTr isozymes from major organs are available (Jakoby and Habig, 1980; Mannervik, 1985). In contrast to this, very little is known about GSHTr from skin. Earlier reports have shown the presence of GSHTr activity in rodent skin cells grown in culture (Coomes et al., 1983; Kawashima et al., 1984) and in skin cytosol (Hayakawa et al., 1974; Mukhtar and Bresnick, 1976; Mukhtar and Bickers, 1981, 1983; Mukhtar et al., 1981a). Human skin has also been shown to possess GSHTr activity (Mukhtar and Bresnick, 1976; Mukhtar et al., 1981b). A brief report based on qualitative immunochemical analysis suggested the presence of multiple forms of cutaneous GSHTr in adult rat (Redick et al., 1982). It is noteworthy that all the previous studies were performed with crude preparations of cutaneous GSHTr. In this communication, we report for the first time the isolation and partial purification of two groups of GSHTr from skin cytosol of neonatal rats using affinity chromatography and HPLC and some biochemical properties of the major form.

*To whom correspondence should be addressed.

Abbreviations: CDNB, 1-chloro-2,4-dinitrobenzene; GSH, reduced glutathione; DTT, dithiothreitol; HPLC, high performance liquid chromatography; GSHTr, glutathione S-transferase(s).

\section{MATERIALS AND METHODS}

\section{Materials}

CDNB and 1,2-naphthoquinone were purchased from Aldrich Co., Wisconsin, USA. GSH and DTT were obtained from U.S. Biochemical Co. The Sepharose 4B, and $17 \beta$-estradiol-3-sulfate were the products of Sigma Chemical Co. Triphenyltin chloride was from Alfa Products, USA.

\section{Animals}

Three day old neonates of inbred CFN rats were used.

\section{Enzyme isolation}

Rats were killed by cervical dislocation. The skins were removed and immediately placed in ice-cold $50 \mathrm{mM}$ Tris$\mathrm{HCl}$ buffer, $\mathrm{pH} 7.2$ containing $0.25 \mathrm{M}$ sucrose (Buffer-A). Each skin was spread epidermal side down on a petridish and the dermis was cleared of fat and muscle by careful scraping with a blunt scalpel. The skins (from 25-30 rats/preparation) were weighed, minced and homogenized in ice-cold buffer-A ( $20 \%$ homogenate, $w / v)$ using an UltraTurrax tissue homogenizer (six $20 \mathrm{sec}$ bursts with $40 \mathrm{sec}$ intervals for cooling). The homogenates were sonicated for $10 \mathrm{sec}$, rehomogenized in a glass-Teflon homogenizer, and centrifuged at $39,000 \mathrm{~g}$ for $30 \mathrm{~min}$ at $4^{\circ} \mathrm{C}$. the supernatant (cytosol) was carefully decanted and used as the enzyme source.

\section{Affinity chromatography}

In a typical experiment, cytosol containing about $7 \mathrm{U}$ of GSHTr was applied to the column $(2.8 \times 6.0 \mathrm{~cm})$ of GSH coupled epoxy-activated Sepharose 4B, which was preequilibrated with $50 \mathrm{mM}$ Tris- $\mathrm{HCl}$ buffer, pH 7.4 at $4^{\circ} \mathrm{C}$. The affinity chromatography of cutaneous GSHTr was conducted as described previously (Radulovic and Kulkarni, 1985). 


\section{High performance liquid chromatography}

HPLC was performed as described previously (Radulovic and Kulkarni, 1985) with some modifications. The mobile phase consisted of $10 \mathrm{mM}$ potassium phosphate buffer containing $1.0 \mathrm{mM}$ DTT and $10 \mathrm{mM}$ GSH, $\mathrm{pH} 7.2$ (buffer-B), and buffer- $\mathrm{C}$ containing $0.4 \mathrm{M} \mathrm{KCl}$ in buffer-B. Prior to HPLC, the eluate from the affinity column was concentrated by ultrafiltration using PM-10 membrane, and dialyzed overnight against buffer-B. An aliquot $(0.5-1.0 \mathrm{ml})$ was injected onto the anion exchange column (Synchrom AX-300 from Synchrom, Linden, IN, USA) and eluted with salt gradient. The program used was as follows: Flow rate of $1.0 \mathrm{ml} / \mathrm{min}$ and $\%$ buffer-C $=0$ at time $(t)=0 ; \%$ buffer-C was increased to 7.5 in $3 \mathrm{~min}$, beginning at $t=5 \mathrm{~min} ; \%$ buffer-C was further increased to 100 in $5 \mathrm{~min}$ at $t=8 \mathrm{~min}$; re-equilibration began at $t=21 \mathrm{~min}$, at which time $\%$ buffer- $\mathrm{C}$ was decreased to 0 over $2 \mathrm{~min}$ and the flow was maintained at $2.0 \mathrm{ml} / \mathrm{min}$ for $15 \mathrm{~min}$. The HPLC effluent was collected in $1.0 \mathrm{ml}$ fractions and assayed for GSHTr activity. Those fractions exhibiting GSHTr activity peaks were combined.

\section{Enzyme assay}

GSHTr activity toward CDNB was determined at $37^{\circ} \mathrm{C}$ using an Amino DW-2, as described previously (Radulovic and Kulkarni, 1985). Duplicate assays were performed with a rate-limiting enzyme concentration. One enzyme unit is defined as the amount of enzyme that causes formation of $1.0 \mu$ mole of CDNB-conjugate $/ \mathrm{min} / \mathrm{mg}$ protein. In kinetic and inhibition experiments, the pooled fractions from P-1 peak were concentrated by ultrafiltration using PM-10 membrane and dialyzed against $10 \mathrm{mM}$ potassium phosphate buffer, pH 7.2 containing $0.1 \mathrm{mM} \mathrm{GSH}$ before use. Inhibitors were incubated with the enzyme in buffer for $3 \mathrm{~min}$ at $37^{\circ} \mathrm{C}$, prior to the addition of GSH and CDNB. Mercuric chloride was dissolved in deionized water. All other inhibitors were dissolved in $95 \%$ ethanol. The reported data are corrected for solvent effects.

Protein content of the cytosol was determined by the method of Lowry et al. (1951), while the dye binding assay of Bradford (1976) was utilized in subsequent purification steps.

\section{RESULTS}

Table 1 summarizes the results of the experiments on the purification of GSHTr from skin cytosol of 3-day-old rats using the two-step procedure. GSHTr adsorbed on the affinity matrix eluted as a single peak (not shown) with an average recovery of about $85 \%$. The affinity chromatography step alone resulted in a 615 -fold purification of the enzyme. The GSHTr isozymes present in the 4B-GSH concentrate were resolved into 2 peaks of activity by HPLC. The chromatographic profile of GSHTr elution from the HPLC column observed in a typical experiment is depicted in Fig. 1. The recovery of GSHTr activity during HPLC step was about $82 \%$. Approximately $80 \%$ of the total recovered GSHTr activity was present in the major peak (P-1), with a retention time of $4.8 \mathrm{~min}$. This peak emerged from the column just

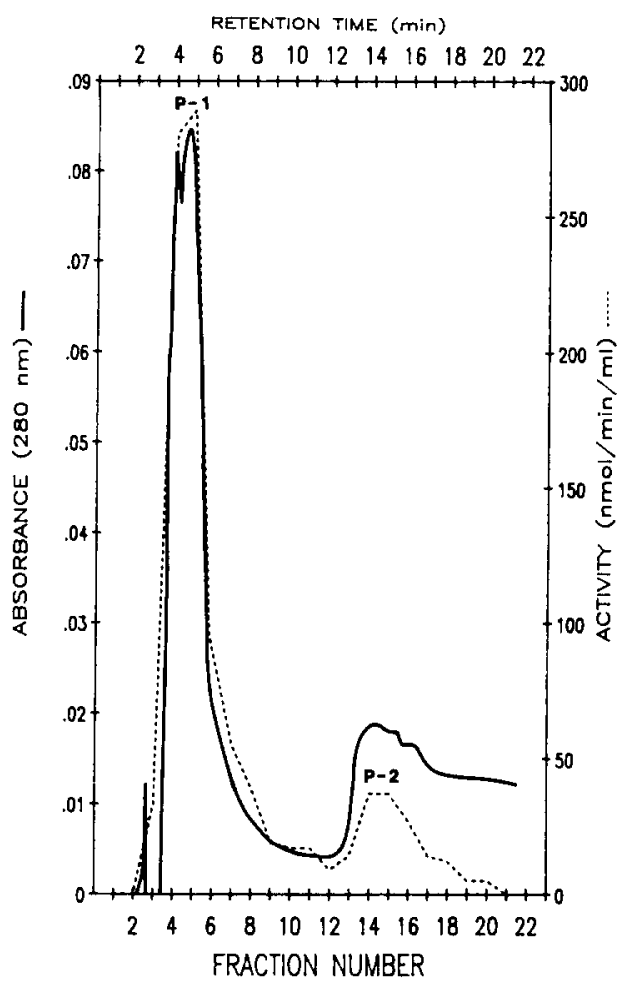

Fig. 1. HPLC chromatographic profile of GSHTr. Chromatography was performed as described in Materials and Methods. Protein content was monitored at $280 \mathrm{~nm}$ ( $\longrightarrow$ ). Specific activity of GSHTr $(\ldots .$.$) is expressed in nmoles of$ CDNB-conjugate formed $/ \mathrm{min} / \mathrm{ml}$ effluent. All fractions contained a $1.0 \mathrm{ml}$ volume.

after the void volume and before the salt gradient. The observed average specific activity of $73 \mu$ moles of CDNB-conjugate formed $/ \mathrm{min} / \mathrm{mg}$ protein for $\mathrm{P}-1$ corresponds to an overall purification of 2271 -fold (Table 1). The minor peak (P-2) represented about $10 \%$ of the recovered activity, with a retention time of about $14 \mathrm{~min}$. The remaining $10 \%$ of the recovered activity was distributed in low amounts on the fractions which did not constitute P-1 and P-2.

Three separate enzyme preparations were used to evaluate the kinetic parameters of the cutaneous GSHTr. The GSH concentration was kept constant at $2.5 \mathrm{mM}$ for the determination of $K_{m}$ and $V_{\max }$ for CDNB; while $1.0 \mathrm{mM}$ CDNB was employed for the evaluation of the same parameters for GSH. The estimated values for the kinetic parameters examined are presented in Table 2. Representative Lineweaver-Burk plots of the kinetic data (Sample 3, Table 2) are shown in Figs 2 and 3. Approximately 2 -fold variation in the $K_{m}$ and up to 5 -fold variation in the $V_{\max }$ values was noted with the enzyme preparations used.

Table 1. Partial purification of the neonatal rat cutaneous GSHTr

\begin{tabular}{lccc}
\hline Fraction & $\begin{array}{c}\text { Specific activity* } \\
(\mu \text { moles } / \mathrm{min} / \mathrm{mg})\end{array}$ & $\begin{array}{c}\text { Pecovery } \\
(\%)\end{array}$ \\
\hline Supernatant & $0.032 \pm 0.002$ & 1 & 100 \\
4B-GSH & $19.690 \pm 4.024$ & 615 & 85 \\
HPLC & $72.667 \pm 14.769$ & 2271 & 65 \\
\hline
\end{tabular}

*Values reported are mean $\pm \mathrm{SE} .(n=3)$. 
Table 2. Kinetic parameters of partially purified rat neonate skin GSHTr from HPLC P-1 Fraction

\begin{tabular}{|c|c|c|c|c|c|}
\hline \multirow[b]{2}{*}{ Sample } & \multirow[b]{2}{*}{ Number } & \multicolumn{2}{|c|}{ CDNB } & \multicolumn{2}{|c|}{ GSH } \\
\hline & & $K_{m}^{*}$ & $V_{\max }^{\dagger}$ & $K_{m}^{*}$ & $V_{\max }^{+}$ \\
\hline & 1 & 1.98 & 88.25 & 0.59 & 55.00 \\
\hline & 2 & 3.69 & 433.00 & 0.56 & 132.00 \\
\hline & 3 & 1.50 & 116.00 & 1.01 & 115.00 \\
\hline Mean & & 2.39 & 212.42 & 0.72 & 100.67 \\
\hline$\pm \mathrm{SE}$ & & 0.67 & 110.58 & 0.15 & 23.35 \\
\hline
\end{tabular}

*Expressed as $\mathrm{mM}$ concentrations.

†Expressed as $\mu$ mole CDNB-conjugate formed $/ \mathrm{min} / \mathrm{mg}$ protein.

Experiments were also performed in which the relative ability of selected inhibitors to inactivate cutaneous GSHTr was examined. Several pilot experiments were performed to determine inhibitor concentration that could produce approx. $50 \%$ inhibition of the GSHTr activity. Due to a limited availability of the partially purified enzyme, detailed analyses were not possible. GSHTr present in only the P-1 fractions obtained after HPLC were used in these studies. Among the compounds tested, triphenyltin chloride and 1,2-naphthoquinone were found to be potent inhibitors of the enzyme. The \% inhibition (mean $\pm \mathrm{SE}, n=3$ ) of GSHTr activity observed in the presence of different inhibitors was as follows: $67.1 \pm 3.2$ with $200 \mu \mathrm{M} \mathrm{HgCl}_{2} ; 58.1 \pm 9.2$ with $1.0 \mu \mathrm{M}$ triphenyltin chloride; $55.9 \pm 6.3$ with $0.63 \mu \mathrm{M} 1,2$-naphthoquinone; and $42.8 \pm 11.5$ with $12.5 \mu \mathrm{M} 17-\beta$-estradiol-3-sulfate. Specific activity in the controls ranged from 21.4 to $72.0 \mu$ moles CDNBconjugate formed $/ \mathrm{min} / \mathrm{mg}$ protein. Under the experi-

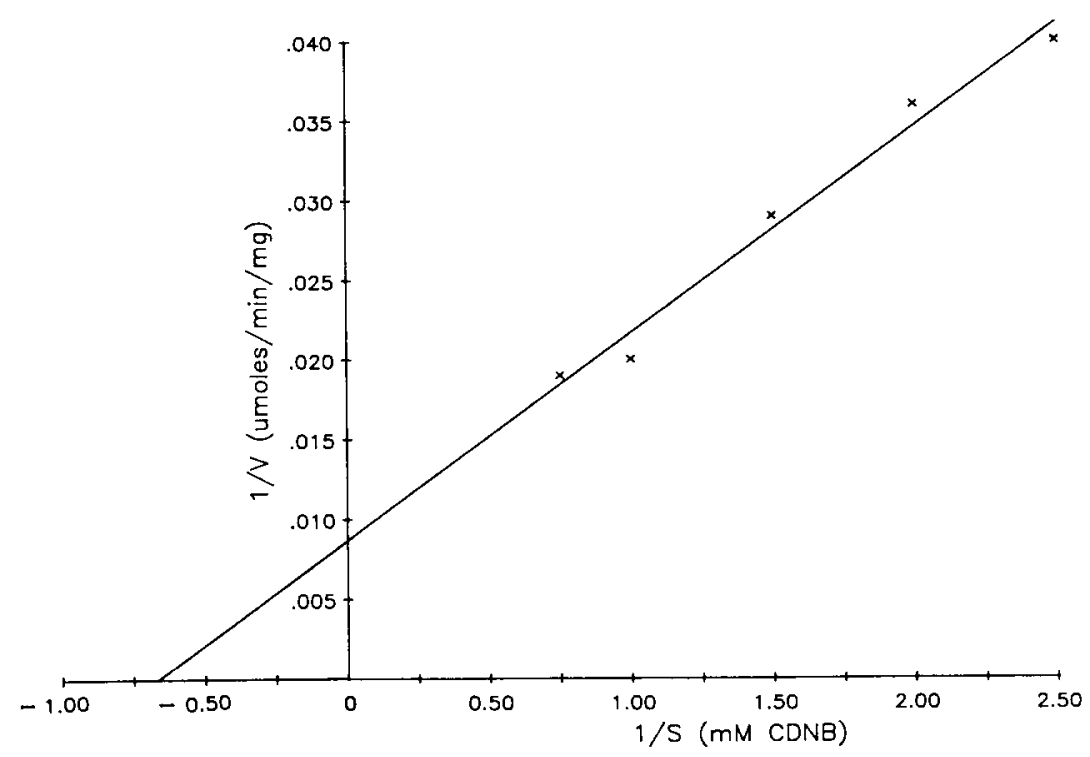

Fig. 2. Lineweaver-Burk plot of cutaneous glutathione S-transferase showing the effect of CDNB concentration on initial velocity. Assays were performed as described in Materials and Methods.

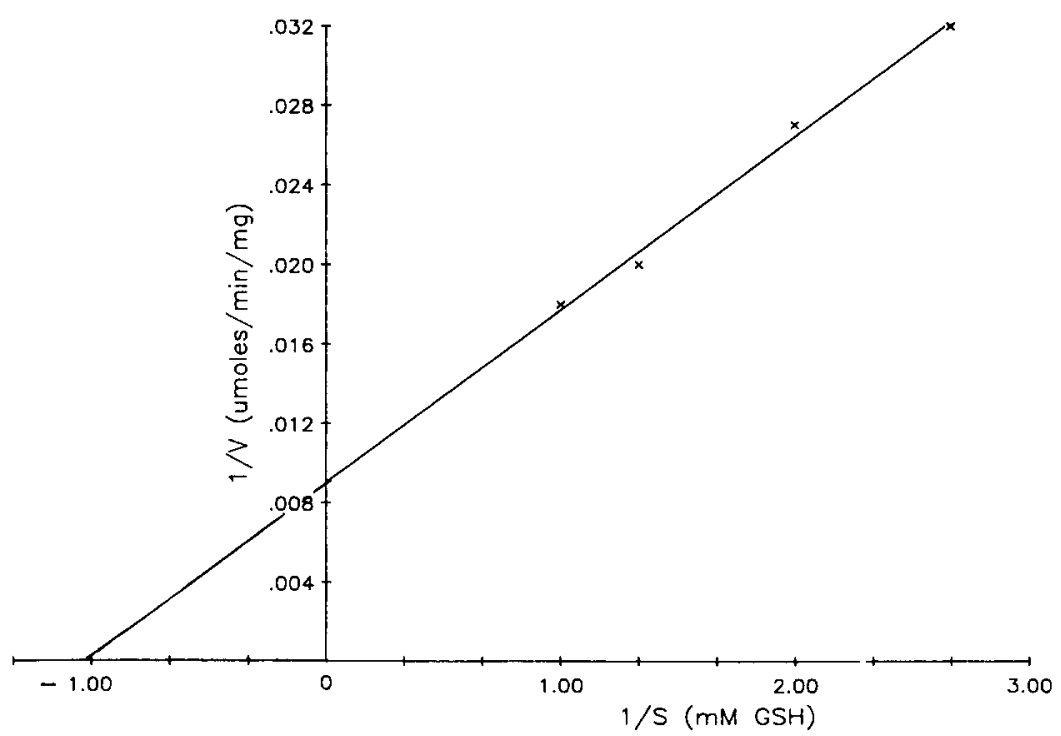

Fig. 3. Lineweaver-Burk plot of cutaneous glutathione S-transferase showing the effect of reduced glutathione concentration on intial velocity. Assays were performed as described in Materials and Methods. 
mental conditions employed, all the chemical tested caused significant inhibition $(p=0.05)$, as determined statistically by paired- $t$ analysis.

\section{DISCUSSION}

Irrespective of the tissue source, overlapping substrate specificity is a known qualitative property of all the isozymes of GSHTr studied thus far. Quantitatively however, marked differences in substrate specificity between GSHTr isozymes do exist in different mammalian tissues (Chasseaud, 1979; Jakoby and Habig, 1980; Mannervik, 1985). CDNB has been most commonly used to measure tissue GSHTr titers since it serves as a substrate for all the known isozymes of GSHTr (Jakoby and Habig, 1980; Mannervik, 1985). In view of this, the previously reported data based on arene oxides as substrates (Mukhtar and Bresnick, 1976; Mukhtar and Bickers, 1981, 1983; Mukhtar et al., 1981 a) possibly reflect on a partial quantitation of GSHTr activity in the cytosolic fractions of neonatal rat skin. This is the first communication reporting the GSHTr activity towards CDNB in the cytosol isolated from neonatal rat skin (Table 1).

Although affinity chromatography yielded substantial purification of cutaneous GSHTr (Table 1), the observed recovery of enzyme in this step (about $85 \%$ ) is much lower than that reported for the human placental GSHTr (Radulovic and Kulkarni, 1985) and this may not be related to the denaturation of the enzyme during chromatography. We believe that the observed incomplete recovery of rat cutaneous GSHTr may be due to the loss of certain isozyme(s) of GSHTr that are not bound to the affinity matrix used. It should be noted that this is not a unique property of the cutaneous GSHTr, since similar results, for at least one form (isozyme 5-5) of rat liver GSHTr, have previously been reported (Robertson et al., 1985).

Similar to the procedure for purification of human placental GSHTr (Radulovic and Kulkarni, 1985), HPLC was found to be a rapid, and effective method of purification of the cutaneous GSHTr. It was possible to resolve the mixture of GSHTr isozymes, isolated by the affinity chromatography, into at least two groups. The chromatographic behaviour suggests that the GSHTrs present in P-2 stongly interact with the column matrix and may be anionic in nature. By the same token, the apparent minimal interaction with the column matrix noted with the GSHTr eluted in $\mathrm{P}-1$ is indicative of either a basic or neutral nature. In the GSHTr activity profiile (Fig. 1), a splitting of the P-1 peak was observed in all the samples analyzed. This suggests that more than one isozyme of GSHTr may be present in P-1. The kinetic data (Table 2) exhibited a wide variation in the results obtained with different enzyme preparations used and this variation, in part, may be due to differences in the ratios of different isozymes present in the P-1 fraction. The $K_{m}$ and $V_{\max }$ values (Table 2) and inhibition data for cutaneous GSHTr are, however, within the range reported for purified GSHTr isozymes from several other tissues (Henry and Byington, 1976; Ohl and Litwack, 1977; Kulkarni et al., 1978; Dierickx,
1982; Mannervik, 1985). In summary, the results indicate that multiple forms of GSHTr exist in the skin cytosol on neonate rats. Although this contention is further supported by an earlier report demonstrating the presence of isozyme $\mathrm{B}, \mathrm{C}$ and $\mathrm{E}$ in adult rat skin by an immunohistochemical technique (Redick et al., 1982), further studies are needed to clearly resolve this issue.

\section{SUMMARY}

Affinity chromatography and HPLC were employed to evaluate the multiplicity of GSHTr in the skin cytosol from 3-day-old rats of CFN strain. The mixture of GSHTr isozymes was resolved into two groups. The major group (isolated as P-1 peak by HPLC) represents about $80 \%$ of the recovered GSHTr activity and appears to be a composite of neutral and/or basic proteins. Kinetic parameters and relative inhibition by the selected chemicals of P-1 GSHTr were evalutated. Strongly anionic form(s) of GSHTr (P-2) also occur in the skin cytosol but in small amounts. Although the number of isozymes present was not determined, the results, in general, suggest multiplicity of GSHTr in the neonatal rat skin.

Acknowledgement-This work was supported, in part, by USAMRDC, contract DAMD17-82-C-2198.

\section{REFERENCES}

Bradford M. M. (1976) A rapid and sensitive method for the quantitation of microgram quantities of protein utilizing the principle of protein dye binding. Analyt. Biochem. 72, 248-254.

Chasseaud L. F. (1979) The role of glutathione and glutathione S-transferases in the metabolism of chemical carcinogens and other electrophilic agents. Adv. Cancer Res. 29, 175-274.

Coomes M. W., Norling A. H., Pohl R. J., Muller D. and Fouts J. R. (1983) Foreign compound metabolism by isolated skin cells from the hairless mouse. J. Pharmac. exp. Ther. 225, 770-777.

Dierickx P. J. (1982) In vitro inhibition of the soluble glutathione S-transferases from rat liver by heavy metals. Enzyme 27, 25-32.

Hayakawa T., Lemahieu R. A. and Udenfriend S. (1974) Studies on glutathione-S-arene oxidase transferase-A sensitive assay and partial purification of the enzyme from sheep liver. Arch. Biochem. Biophys. 182, 223-230.

Henry R. A. and Byington K. H. (1976) Inhibition of glutathione $S$-aryltransferase from rat liver by organogermanium, lead and tin compounds. Biochem. Pharmac. 25, 2291-2295.

Jakoby W. B. and Habig W. H. (1980) Glutathione transferases. In Enzymatic Basis of Detoxification. (Edited by W. B. Jakoby), Vol. 2, pp. 63-94. Academic Press, London. Kawashima T., Yonemoto K., Gellin G. A., Epstein W. L. and Fukuyama K. (1984) Effects of 4-tertiary butyl catechol on glutathione-metabolizing enzymes in vivo and in vitro. J. Invest. Dermatol. 82, 53-56.

Kulkarni A. P., Motoyama N., Dauterman W. C. and Hodgson E. (1978) Inhibition of housefly glutathione S-transferase by catecholamines and quinones. Bull. Environ. Contam. Toxicol. 20, 227-232.

Lowry O. H., Rosebrough N. J., Farr A. L. and Randall R. J. (1951) Protein measurement with Folin phenol reagent J. biol. Chem. 193, 265-275. 
Mannervik B. (1985) Isozymes of glutathione S-transferases. Adv. Enzymol. 57, 357-417.

Mukhtar H. and Bickers D. R. (1981) Drug metabolism in skin: comparative activity of the mixed function oxidases, epoxide hydratase and glutathione S-transferase in liver and skin of the neonatal rat. Drug Metab. Dispos. 9, 311-314.

Mukhtar H. and Bickers D. R. (1983) Age-related changes in benzo(a)pyrene metabolism and epoxide-metabolizing enzyme activities in rat skin. Drug Metab. Dispos. 11, $562-567$.

Mukhtar H. and Bresnick E. (1976) Glutathione S-epoxide transferase in mouse skin and human foreskin. J. Invest. Dermatol. 66, 161-164.

Mukhtar H., Dixit R. and Seth P. K. (1981a) Reduction in cutaneous glutathione content, glutathione S-transferase and arylhydrocarbon hydroxylase activities following topical application of acrylamide. Toxicol. Lett. 9, 153-156.

Mukhtar H., Zoetemelk C. E. M., Baars A. J., Wijnen J. T.,
Blandenstein-Wijnen L. M. M., Khan P. M. and Breimer D. D. (1981b) Glutathione S-transferase activity in human fetal and adult tissues. Pharmacology 22, 322-329.

Ohl V. S. and Litwack G. (1977) Selective inhibition of glutathione S-transferases by $17 \beta$-estradiol disulfate. Arch. Biochem. Biophys. 180, 186-190.

Radulovic L. L. and Kulkarni A. P. (1985) A rapid novel high performance liquid chromatography method for the purification of glutathione S-transferase: An application to the human placental enzyme. Biochem. biophys. Res. Commun. 128, 75-81.

Redick J. A., Jakoby W. B. and Baron J. (1982) Immunohistochemical localization of glutathione S-transferases B, C, and E in liver and skin. Fedn Proc. 41, Abstract 1573.

Robertson I. G. C., Jensson H., Guthenberg C., Tahir M. K., Jernstrom B. and Mannervik B. (1985) Differences in the occurrence of glutathione transferase isozymes in rat lung and liver. Biochem. biophys. Res. Commun. 127, $80-86$. 